of capacity to provide consent, a responsible carer shall provide such consent.

\section{Part VIII: Patients involved in criminal proceedings}

The courts may issue orders for observation in a mental health facility in order to assess the mental capacity of persons charged with a criminal offence for periods of 3 months, renewable. Power to order the discharge of a person detained in a mental healthcare facility upon the plea of insanity can be exercised by the court after a recommendation to the court by three specialists, one of whom is the responsible specialist. Leave of absence may still be granted by the minister responsible for justice in the context of a multidisciplinary treatment plan.

\section{Part IX: Mental health licensed facility}

All facilities which provide a mental health service will continue to be duly licensed as currently provided. However, facilities which provide services to persons detained on an involuntary basis, minors, and forensic patients (persons concerned in criminal proceedings and prisoners) need a specific licence to operate. Every licensed facility must have written patient care management protocols and operational guidelines for implementation of the requirements imposed by the new legislation.

\section{Part X: Promotion of social inclusion}

The law emphasises the need for social inclusion, and gives the Commissioner an advocacy role with legislative bodies to make recommendations on social policy. This part also gives the Commissioner an executive role in taking appropriate action against discrimination or exploitation of persons by reason of their mental health status.

\section{Conclusion: challenges and opportunities}

The new Act explicitly states a set of values and principles: the promotion of patient autonomy; care delivered to persons integrated in their community; the use of the least restrictive methods of care; and a managerial approach, with defined time frames, care plans and goals. It is expected to provide logistic challenges in its implementation, but if these are met, it can be expected that mental healthcare in Malta will reflect the progress made in clinical and academic psychiatry.

\section{References}

Engel, G. L. (1980) The clinical application of the biopsychosocial model. American Journal of Psychiatry, 137, 535-544.

National Statistics Office (2011) Demographic Review 2010. At http://www.nso.gov.mt/statdoc/document_file.aspx?id=3173 (accessed February 2013).

Saliba, J. R. (1994) Psychiatry in Malta. Psychiatric Bulletin, 18 368-370.

\section{RESEARCH} PAPER

\title{
A survey of the mental healthcare systems in five Francophone countries in West Africa: Bénin, Burkina Faso, Côte d'Ivoire, Niger and Togo
}

\author{
Djibo Douma Maiga ${ }^{1}$ and Julian Eaton ${ }^{2}$
}

${ }^{1}$ Coordinateur, Programme National de Santé Mentale Hôpital National de Niamey, Niger

2Senior Mental Health Advisor, CBM International West Africa Regional Office, Lomé, Togo, email julian.eaton@cbm-arow. org

A French translation of this paper is available on request from the corresponding author

Une traduction française de ce document est disponible sur demande auprès de l'auteur correspondant
Sub-Saharan Africa has a wide mental health treatment gap, with low levels of access to mental health services. This paper presents the findings of systematic situation analyses carried out in five Francophone countries in West Africa, which are among the poorest in the world. The findings showed low levels of budgetary allocation to mental health, poor health infrastructure (especially at primary level) and unequal distribution of human and financial resources. In this challenging context, there are signs of reform of services, based on international best-practice guidelines and practical considerations such as decentralisation of services, task-sharing and strengthening stakeholder skills to advocate for change.
Finding a way to respond to the huge burden of mental illness is a major public health challenge, particularly in low-income countries, where $76-85 \%$ of people with severe mental disorders receive no treatment (World Mental Health Survey Consortium, 2004).

In this paper, we assess aspects of mental healthcare in five Francophone countries of West Africa (Bénin, Burkina Faso, Côte d'Ivoire, Niger and Togo) and how they are reforming services to make them more accessible.

\section{Method}

The comparison uses situation analysis studies conducted in Côte d'Ivoire (2013), Togo (2012), Burkina Faso (2011) and Niger (2011) to guide 
This review was based largely on country situation analyses sponsored by CBM International, and carried out by the following and cars in mental health in the phone countries in West Africa. We gratefully acknowledge their commitment and work:

Burkina Faso - M. Pale Koffi;

Côte d'Ivoire - Dr Brou

N'Guessan Prof. Joseph

Delafosse;

Niger - Dr Djibo Douma Maiga; Togo - Professor Valentin Dassa, Dr Kokou Messanh Soedje

J.E. works for CBM, which sponsored the situation analyses used as the raw data in this pape D.D.M. works for the Government of Niger as the National Mental Health Programme Coordinator

Table 1

Framework demographic data

\begin{tabular}{|l|l|l|l|l|l|}
\hline & Bénin & Burkina Faso & Côte d'Ivoire & Niger & Togo \\
\hline Population (millions) & 10.05 & 17.00 & 19.84 & 15.20 & 6.10 \\
\hline Area $\left(\mathrm{km}^{2}\right)$ & 114763 & 274200 & 322462 & 1267000 & 56785 \\
\hline Population density (persons per km ${ }^{2}$ ) & 60 & 51.8 & 65.3 & 12.5 & 95 \\
\hline Expenditure on health (\% of gross domestic product) & 4.6 & $15.46^{a}$ & 4.34 & 6 & 4.36 \\
\hline Life expectancy at birth & 56.5 & 55.9 & 56.0 & 55.1 & 57.5 \\
\hline $\begin{array}{l}\text { Human Development Index, 2012 } \\
\text { (and rank out of 186 countries) }\end{array}$ & 0.459 & 0.332 & 0.444 & 0.313 & 0.542 \\
\hline Literacy rate (\%) & $(166)$ & $(183)$ & $(168)$ & $(186)$ & $(159)$ \\
\hline
\end{tabular}

The budgeting of other ministries and institutions related to health were included from 2008

${ }^{6}$ Non-income Human Development Index (HDI): United Nations Development Programme (UNDP) statistics from http://hdr.undp.org/en/countries/

collaborative mental health work between government ministries and CBM, an international development organisation. The information was used to plan evidence-based interventions, appropriate for the country, based on the World Health Organization's mhGAP programme (WHO, 2008). In Bénin, data were taken from the World Health Organization's AIMS report (WHO, 2011a).

A common framework was used for each analysis, based on recognised structured assessment tools (Cohen et al, 2011), principles for effective integration with general healthcare (WHO, 2001) and information useful for programme development.

\section{Context}

West Africa is among the poorest regions in the world, reflected in very low Human Development Index rankings (Table 1), particularly for Niger. Côte d'Ivoire has historically had a stronger economy, but this was set back by the civil war of 2002-11. Life expectancy and literacy rates are also low regionally (Table 1), reflecting weak health, education and social services.

In each country, government spending on mental health is low: less than $1 \%$ of health budgets (WHO, 2011b). Non-governmental organisations provide financial and technical support, either through government systems or in private and religious/humanitarian services. Civil society organisations also act as forums for advocacy around disability, human rights and related issues.

The five countries were all French colonies until independence in the early 1960s, and this legacy has resulted in similar administration of health systems.

None of the five countries possesses detailed information about mental, neurological or substance use (MNS) disorders in decentralised services. There are few primary-level or community mental health services. Health information systems at the primary level do not distinguish MNS disorders as distinct categories. Such data are either completely absent or limited to broad categories such as 'mental illness'. This is one of the obstacles to the development of community mental healthcare, because planning has always been based exclusively on hospital data (Patel \& Kleinman, 2003).
Community studies are rare, and not usually undertaken by government, so are not considered in planning (Gureje \& Alem, 2000).

\section{Mental health needs and beliefs}

There are limited published data on prevalence in the region. All the countries provided statistics based on presentation to services in major centres, but there were no good epidemiological data from community-level surveys. The main presentations in hospital statistics were psychotic disorders, depression, anxiety disorders, bipolar disorder and epilepsy, with no significant differences between countries. In all these countries, there were raised risk factors for mental illness such as poverty, malnutrition and inequity of access to health services; in addition, war has been a recent experience in West Africa.

The five countries surveyed are ethnically diverse and have populations who are of Christian, Muslim and traditional religious persuasions. In general, Christianity is more common in the south and coastal parts of the region, with Islam more common to the north. In practice, traditional polytheistic beliefs are widely followed by members of communities who describe themselves as Muslim or Christian. This is very relevant to healthseeking behaviour, with mental illness commonly considered to have a spiritual cause, and people typically turn to traditional or religious healers first.

Traditional treatments are of course peculiar to different areas and ethnic groups, but often take the form of herbal remedies or ceremonies against possession. Christian and Muslim leaders offer prayer or perform ceremonies to respond to the perceived spiritual cause of emotional distress or socially unacceptable behaviour. Some are identified as experts in this area. Unfortunately, in all the countries, human rights abuse has been reported in traditional or religious settings, and such establishments have often become places of long-term containment.

When faced with long-lasting or relapsing conditions, families often try several types of care, sometimes including travelling to a specialist hospital. All these options are expensive, sometimes catastrophically so for families. 
Table 2

Policies, plans and legislation in mental health

\begin{tabular}{|c|c|c|c|c|c|}
\hline & Bénin & Burkina Faso & Côte d'Ivoire & Niger & Togo \\
\hline Mental health policy & Policy in place & \multicolumn{4}{|c|}{$\begin{array}{l}\text { Specific mental health strategic plans or general health strategy includes mental } \\
\text { health items }\end{array}$} \\
\hline $\begin{array}{l}\text { Services programme coordination of mental health activities: } \\
\text { national directorate (all have coordinator) }\end{array}$ & Yes & Created in 1993 & Created in 2007 & Created in 1993 & Created in 1994 \\
\hline Strategic plan for mental health (last valid plan) & 2009-18 & $2011-20$ & 2013-15 & $2010-14$ & $2012-15$ \\
\hline Legislation $^{a}$ & $\begin{array}{l}\text { Code of Persons } \\
\text { and the Family } \\
\text { (articles } 457,458 \text { ) } \\
\text { and Penal Code }\end{array}$ & $\begin{array}{l}\text { Integrated in } \\
\text { other laws }\end{array}$ & $\begin{array}{l}\text { Civil Code } \\
\text { (articles } \\
489-512 \text { ) }\end{array}$ & $\begin{array}{l}\text { Drafted but not } \\
\text { yet adopted }\end{array}$ & $\begin{array}{l}\text { Civil Code } \\
\text { (articles 489- } \\
\text { 515) and Penal } \\
\text { Code (article 411) }\end{array}$ \\
\hline Civil society & \multicolumn{5}{|c|}{$\begin{array}{l}\text { Each country has local, regional or national mental health organisations, but none are managed by } \\
\text { people with mental health problems themselves, or carers }\end{array}$} \\
\hline
\end{tabular}

${ }^{a}$ Draft legislation exists in Niger and is being elaborated in Bénin.

Table 3

Provision of mental health services

\begin{tabular}{|c|c|c|c|c|c|}
\hline & Bénin & Burkina Faso & Côte d'Ivoire & Niger & Togo \\
\hline $\begin{array}{l}\text { Number of mental healthcare specialists }{ }^{a} \text { per } \\
100000 \text { population }\end{array}$ & 0.16 & 0.70 & 0.59 & 0.29 & 0.10 \\
\hline Mental health training schools for medical doctors & 1 & 1 & 1 & 0 & 0 \\
\hline Mental health training schools for general nurses & 0 & 1 & 1 & 1 & 1 \\
\hline Tertiary services & $\begin{array}{l}\text { University Neuro } \\
\text { Psychiatric Centre } \\
\text { of Jacquot and a } \\
\text { psychiatry department } \\
\text { at Borgou Hospital }\end{array}$ & $\begin{array}{l}\text { Psychiatry } \\
\text { departments at } \\
\text { Yalgado Ouédrago } \\
\text { Hospital (Ouaga) } \\
\text { and Bobo Dioulasso }\end{array}$ & $\begin{array}{l}\text { Psychiatric } \\
\text { hospitals of } \\
\text { Bengerville } \\
\text { (1962) and } \\
\text { Bouake (1970) }\end{array}$ & $\begin{array}{l}\text { Psychiatry } \\
\text { departments at } \\
\text { National Hospitals } \\
\text { of Niamey (1956) } \\
\text { and Zinder }\end{array}$ & $\begin{array}{l}\text { Psychiatric centre } \\
\text { of Zébé (1904) } \\
\text { and psychiatry and } \\
\text { psychology clinical } \\
\text { service of Tokoin, Lomé }\end{array}$ \\
\hline $\begin{array}{l}\text { Proportion of regions with psychiatric units in } \\
\text { general hospitals, or secondary hospitals providing } \\
\text { mental healthcare }\end{array}$ & $4 / 6$ & $9 / 9$ & $11 / 17$ & $8 / 8$ & $0 / 6$ \\
\hline $\begin{array}{l}\text { Proportion of districts with primary-level services } \\
\text { providing mental healthcare }\end{array}$ & $0 / 34$ & $27 / 42$ & $3 / 48$ & $3 / 42$ & $0 / 35$ \\
\hline Psychiatric beds per 100000 & 0.44 & 0.85 & 1.3 & 0.95 & 1.80 \\
\hline
\end{tabular}

a Mental healthcare specialists are both psychiatrists and nurses skilled in mental healthcare. It is important to note that the discussion has focused on the status of psychologists in mental healthcare, but many are not clinically trained.

${ }^{b}$ Secondary-level health services at named regional hospital centres in the five countries.

\section{Policies and legislation in mental health}

The study highlights a lack of mental health policies in these countries. Bénin developed, validated and adopted a mental health policy in 2009, but it is not well endorsed. In the other four countries, the annual health strategic plan routinely has a mental health component (Table 2) but this is rarely implemented.

Laws relating to mental illness are enshrined in the colonial order of 1938 establishing a psychiatric service in French West Africa (Collignon, 1978), and some legislation defines how mental illness should be treated in the criminal code. Despite the fact that all five countries have signed the UN Convention on the Rights of Persons with Disabilities, and all but Côte d'Ivoire have gone on to ratify it, current legislative practice fails to protect these rights.

\section{Governance, services and the provision of mental healthcare}

\section{Governance}

Administratively, each country has a national coordinator in the Ministry of Health, who is generally the senior psychiatrist in the country. In all cases, mental health is a small department under 'non-communicable diseases', with little political impact, as this field has not been a priority. One result is the allocation of few resources to mental health, so although policy exists, and strategic plans are developed, these are hardly ever budgeted for, beyond maintenance of existing core (hospital) services and staff salaries. Increased interest from the international community, including agencies such as the World Health Organization, which launched a Global Mental Health Action Plan in 2013, is starting to change this.

Services are unevenly distributed geographically, with the great majority based in the capital cities. Studies in the region suggest that only around $15 \%$ of people with severe mental illness access care (Gureje \& Lasebikan, 2006). This rate is likely to be the same or worse in the Francophone countries, which generally have fewer resources.

At the tertiary level, all five countries have psychiatric hospitals and/or a department of psychiatry in teaching hospitals. Despite hospitalbased care being the strongest sector in all these countries, the availability of hospital beds is low (Table 3), with just a few in general hospitals.

At the secondary level of care, services are limited. In the early 2000 s there was a successful process of decentralisation in Burkina Faso, which 
resulted in many regions having a mental health unit in general hospitals, staffed by a specialist mental health nurse. In other countries, less than $10 \%$ of regional or district hospitals have a person dedicated to mental health.

Besides government services, non-profit, faithbased organisations provide care in each country. There are two mental health centres in Bénin, four in Côte d'Ivoire and three in Togo. In addition, the psychiatrists in each country run private clinics in the capital cities.

The provision of psychotropic drugs in these five countries is characterised by unreliability of supply and poor quality (McBain et al, 2012) at both primary and secondary levels of the health pyramid. Psychotropic drug supplies are much more reliable at the tertiary level and in the largest private pharmacies, but these medications are expensive, making long-term use of them impossible for most of the population.

Psychological and social interventions are available only at tertiary hospitals in some countries (Burkina Faso, Niger, Côte d'Ivoire). While in Togo there is a relatively large number of psychology graduates, they are not appropriately trained or employed for clinical work. Each country has a Ministry of Social Welfare, but there is little communication between sectors, with no dedicated social workers for people with mental health problems.

\section{Human resource development}

Côte d'Ivoire and Burkina Faso have been training mental health specialist nurses and doctors for at least two decades. They therefore have more mental health staff than the other three countries. In Bénin, despite training specialists in mental health since 1985, levels remain low due to the length of training, and because there is little interest in this specialty, due to stigma. Niger and Togo have offered training in mental health nursing since 2007 and 2012, respectively.

\section{Discussion}

Mental healthcare in these five countries is going through a period of reform. The absence of a policy framework has hindered this process, with the other main barrier being lack of personnel. Placing a greater emphasis on non-specialists providing care (task-sharing), with specialists mainly supervising, would alleviate this problem.

Poor supply of essential psychotropic medicines and poor health information management were also consistent findings. Decentralisation and provision of services at the primary-care level is probably the main priority. The five countries currently have pilot projects informed by mhGAP, either complete (Bénin), in progress (Niger) or due to commence (Burkina Faso, Côte d'Ivoire and Togo). Generally, these involve taking a systems approach to coordination and integration of mental health into routine health services (information systems, medication), building personnel capacity, ensuring ongoing support and supervision, and strengthening civil society networks in mental health. The impact of these pilots is difficult to predict. It is hoped that in a context of ongoing advocacy with government, scale-up can follow. They have certainly raised the profile of mental health in the countries; for example, some extra resources have already been released in Niger to expand the programme. International partners have primed and helped implement these pilots. In the current economic environment, such private-public partnership is essential in leveraging at least some of the resources necessary for scale-up.

In several of the countries, organisations already exist that involve users and their families in community-based rehabilitation (parts of Burkina Faso, Niger, Togo and Bénin), or provide other non-governmental, mainly faith-based, services.

\section{Conclusion}

This comparison found similar environments of great need and limited resources across the region. The political and health systems had many parallels, which allows approaches to service reform to be shared. There is now a growing understanding of the importance of integration into general health systems, geographical decentralisation, and working through other sectors. This more integrated approach, coupled with the use of nonspecialists in care provision, means that the wide mental health gap may be bridged in a practical way in these low-resource settings.

\section{References}

Cohen, A., Eaton, J., Radtke, B., et al (2011) Three models of community mental health services in low-income countries. International Journal of Mental Health Systems, 5, 3.

Collignon, R. (1978) Vingt ans de travaux à la clinique psychiatrique de Fann-Dakar. [Twenty Years of Work at the Psychiatric Clinic of Dakar-Fann.] Société de psychopathologie et d'hygiène mentale. Available at http://www.rag.sn/sites/psychopathologie.refer.sn/IMG/ pdf/Biblio20ansPsy.pdf (accessed July 2013).

Gureje, O. \& Alem, A. (2000) Mental health policy in Africa. Bulletin of the World Health Organization, 3, 1106.

Gureje, O. \& Lasebikan, V. O. (2006) Use of mental health services in a developing country. Results from the Nigerian survey of mental health and well-being. Social Psychiatry and Psychiatric Epidemiology, 41, 44-49.

McBain, R., Norton, D. J., Morris, J., et al (2012) The role of health systems factors in facilitating access to psychotropic medicines: a cross-sectional analysis of the WHO-AIMS in 63 low- and middleincome countries. PLoS Medicine, 9(1), e1001166.

Patel, V. \& Kleinman, A. (2003) Poverty and common mental disorders in developing countries. Bulletin of the World Health Organization, 81, 609-615.

WHO (2001) World Health Report Mental Health: New Understanding, New Hope. World Health Organization.

WHO (2008) Mental Health Gap Action Programme: Scaling Up Care for Mental, Neurological and Substance Use Disorders. WHO Department of Mental Health and Substance Abuse.

WHO (2011a) WHO-AIMS Report on the Mental Health System in the Republic of Benin. WHO. Available at http://www.who.int/ mental_health/WHO-AIMS_benin_English.pdf (accessed July 2013).

WHO (2011b) Mental Health Atlas. WHO. Available at http://www. who.int/mental_health/publications/mental_health_atlas_2011/en/ (accessed July 2013)

World Mental Health Survey Consortium (2004) Prevalence, severity, and unmet need for treatment of mental disorders in the WHO World Mental Health Surveys. JAMA, 291, 2581-2590. 